www.jmscr.igmpublication.org

Impact Factor 5.84

Index Copernicus Value: 83.27

ISSN (e)-2347-176x ISSN (p) 2455-0450

crossref DOI: https://dx.doi.org/10.18535/jmscr/v5i2.76

Journal Of Medical Science And Clinical Research

\title{
Bacterial and Fungal Flora on Stethoscopes of Healthcare Workers in Navi Mumbai and Effective use of $70 \%$ Isopropyl Alcohol as a Disinfectant
}

Authors

\author{
N.Kamath ${ }^{1}$, R.Swaminathan ${ }^{2}$, A.Prabhu ${ }^{3}$
}

${ }^{1}$ Associate Prof., Dept.of Microbiology, World College of Medical Sciences \& Research, Jhajjar, Haryana ${ }^{2}$ Professor \& H.O D, Dept of Microbiology, D Y Patil University School of Medicine, Nerul, Navi Mumbai. ${ }^{3}$ Research Student, Dept.of Microbiology, D Y Patil University School of Medicine, Nerul, Navi Mumbai Corresponding Author

\section{Dr N.Kamath}

Associate Professor, Dept. of Microbiology, World College of Medical Sciences \& Research and Hospital, Jhajjar, Haryana

Email:nktallur@gmail.com, Mobile: 9967587087

\section{Abstract}

Hospital acquired infections are recognised as critical public health problems. Infections are frequently caused by organisms residing on patient's skin-normal flora and medical equipment including stethoscopes. Nosocomial infections account for morbidity and mortality of patients and increased healthcare cost. This study was undertaken to determine the cleaning practices of their stethoscopes among healthcare providers as stethoscopes can be a potential source of nosocomial infections; and to compare the effectiveness of the commonly used antiseptic- 70\% isopropyl alcohol in disinfecting stethoscopes. The study group included Associate professors, Assistant Professors, General practitioners, Residents, Interns, Nurses and medical students.

Cleaning/disinfection practices of the stethoscopes by healthcare providers are noted and culture samples were collected by using sterile swabs of 60 stethoscopes and demonstrated the cleaning of diaphragm of the stethoscopes after every patient and 60 post cleaning samples were also collected. All the samples were subjected to bacteriological culture and fungal culture; hence the flora of the stethoscopes were determined.

Results showed that cleaning the stethoscopes with 70\% isopropyl alcohol reduced the bacterial and fungal count by $98-100 \%$.

$30 \%$ (18 of 60) healthcare providers cleaned their stethoscopes daily prior to the survey, 36.66\% (22 of 60) doing it weekly, $10 \%$ (6 of 60) cleaned monthly and 18.33\%(11 of 60) had never cleaned their Stethoscopes or they were cleaning it infrequently. Health care providers were made aware of the flora of the bacteria and fungi residing on their stethoscope and they have promised to clean it regularly. Common isolates were Staphylocooci, Streptococci, E.coli, Klebsiella Spp. Proteus vulgaris, Pseudomonas aeruginosa, Candida Spp, Diphtheroids, Coagulase negative Staphylococcus, Bacillus Spp. and Micrococcus Spp. Aspergillus Spp. Post cleaning with 70\% isopropyl alcohol confirmed that flora can be removed which takes few seconds which can prevent a huge healthcare burden.

Our study confirms that stethoscopes carry bacteria and fungi which can be a potential source of hospital acquired infections which when disinfected regularly can prevent infections and save patients.

Keywords: Stethoscope,Nosocomial infections, CFU, SDA. 


\section{Introduction}

Nosocomial infections (Hospital acquired infections) are acquired from hospital environment which is a reservoir of variety of microorganisms which include Bacteria, Viruses, Fungi and parasites. Fomites carry many bacteria and are responsible for hospital acquired infections. Stethoscopes showed bacterial contamination with highest contamination from Doctor's stethscopes ${ }^{1}$. Stethoscope being the part of basic paraphernalia of the physician when doing the medical examination. In the high patient volume environment stethoscopes often come into direct contact with the patient'sskin (intact or infected). As stethoscope is a non-disposable instrument, it can serve as a potential fomite in the hospital unless regularly disinfected.

Studies have shown to harbour bacteria on the diaphragm, of the stethoscope. Predominant ones are, S.aureus, Corynebacteria, Bacillus, E.coli, Klebsiellae, and others. These include pathogens as well as non-pathogens which are normal flora of the patient's skin. Studies confirm the contamination of bacteria and other microorganisms and their results confirm that stethoscopes can be a potential source of infection ${ }^{1,2}$.

In our study we included doctors who are Associate Professors, Assistant Professors, Resident doctors, interns, General practitioners and nurses who use stethoscopes day by day. The contamination of the stethoscopes particularly the diaphragm has been reported mainly due to lack of regular disinfection (before and after examining every patient). One of the survey reported that $46 \%$ of the general practitioners disinfect their stethoscopes on daily basis and $40 \%$ disinfect their stethoscopes weekly. Our study found out that post cleaning the stethoscopes considerably decreases the bacterial and fungal load which should encourage all health care practitioners to clean their stethoscopes regularly. Stethoscope is an almost universal tool of medical Profession ${ }^{3}$ which can be contaminated with bacteria like Staphylococci.

Every healthcare worker may follow universal safety precautions including cleaning the stethoscope. One of the study shows $7 \%$ never cleaned their stethoscopes ${ }^{4}$. The aware ness of cleaning practice is increasing.

\section{Materials and Methods}

60 stethoscopes were randomly chosen depending on the availability and convenient sampling technique. Study group included Associate Professors, Assistant Professors, Residents, Interns, medical students and nurses from a 1250 bedded tertiary care centre and general practitioners of Navi Mumbai. After specimen collection of precleaning, 60 samples of post disinfected samples were collected. After receiving an informed consent form and questionnaire, samples were collected and transported to Microbiology laboratory. Restructured questions were asked from the doctors for data. Questions included number of years of practice, brand of the stethoscope, frequency of cleaning the stethoscope and type of solution used.

Identification numbers were given and samples were processed. Each swabs dipped in $0.9 \mathrm{~N}$ normal saline and rubbed over the diaphragm of the stethoscope and diaphragm of the stethoscopes are placed on the media and pressed gently so that all the microorganisms on their surface gets transferred to the media then at the same time they are disinfected with 70\% isopropyl alcohol and awareness was given to doctors about disinfection of this important medical device.

Once the alcohol application is air dried again sampling is done for Post cleaning samples.All the samples (60 pre cleaning and +60 post cleaning) were cultured for bacteria and fungi on McConkey's agar, Blood agar and Sabouraud's dextrose agar (SDA) respectively. Culture media were incubated at $37^{\circ} \mathrm{C}$ for 16-24 hours of incubition and SDA were incubated at room temperature for up to 7 days. Colony forming units are counted and identification is done by colony morphology, Gram staining, biochemical reactions. Samples were collected from the diaphragm of the microscope as this is the part which comes in touch with the patient's skin at times. 


\section{JMSCR Vol||05||Issue||02||Pages 17672-17676||February}

All the participants involved in the study are given detailed information of the study and informed consent was taken in written format.Convenient sampling (Either Stethoscope is directly pressed on to the media or sterile swabs are taken and then inoculated by taking aseptic precautions) (60 samples)

For fungal identification, Colony morphology was observed andLacto phenol cotton blue (LPCB) mount is done.

\section{Results}

Table 1: Cleaning practices of stethoscopes by healthcare workers

\begin{tabular}{|c|c|c|c|c|c|c|c|}
\hline Questions & $\begin{array}{l}\text { Associate } \\
\text { Professors } \\
\mathrm{N}=5\end{array}$ & $\begin{array}{l}\text { Assistant } \\
\text { Professors } \\
\mathrm{N}=8\end{array}$ & $\begin{array}{l}\text { Residents } \\
\quad \mathrm{N}=7\end{array}$ & $\begin{array}{c}\text { General } \\
\text { Practitioners } \\
\quad \mathrm{N}=15\end{array}$ & $\begin{array}{c}\text { Interns } \\
\mathrm{N}=5\end{array}$ & $\begin{array}{l}\text { Students } \\
\quad=15\end{array}$ & $\begin{array}{l}\text { Nurses } \\
\quad=5\end{array}$ \\
\hline \multicolumn{8}{|c|}{ How frequently you clean your stethoscope? } \\
\hline Once a day & 1 & 1 & 2 & 1 & 1 & 5 & 2 \\
\hline Once a week & 1 & 3 & 2 & 2 & 1 & 5 & 1 \\
\hline Once a month & 1 & 3 & 3 & 4 & 1 & 3 & 1 \\
\hline $\begin{array}{l}\text { What is the disinfectants } \\
\text { you use? }\end{array}$ & Alcohol & Alcohol & Alcohol & Alcohol & Alocohol & $\begin{array}{c}\text { Sanitizer } \\
\mathrm{s}\end{array}$ & Alcohol \\
\hline $\begin{array}{l}\text { Do you follow hand } \\
\text { washingtechniques before and } \\
\text { after touching every patient? }\end{array}$ & Sometimes & Sometimes & Sometimes & Sometimes & $\begin{array}{c}\text { Yes } \\
\text { Mostly }\end{array}$ & $\begin{array}{c}\text { Yes } \\
\text { Mostly }\end{array}$ & Sometimes \\
\hline
\end{tabular}

Table 2: Source of stethoscopes with number of bacterial CFUs grown

\begin{tabular}{|l|c|c|c|c|c|}
\hline S. No. & Doctors population & Department & $\begin{array}{c}\text { Total No. of } \\
\text { stethoscopes } \\
\text { N=60 }\end{array}$ & $\begin{array}{c}\text { No. of bacterial } \\
\text { CFUs grown } \\
\text { (Pre cleaning) }\end{array}$ & $\begin{array}{c}\text { Post cleaning } \\
\text { With 70\% } \\
\text { isopropyl alcohol }\end{array}$ \\
\hline 1 & Associate Professors & General Medicine+Paediatrics & 5 & 58 & 2 \\
\hline 2 & Assistant Professors & General Medicine+Paediatrics & 7 & 61 & 3 \\
\hline 3 & Residents & General Medicine+Paediatrics & 8 & 64 & 2 \\
\hline 4 & General Practitioners & Private clinics & 15 & 113 & 4 \\
\hline 5 & Interns & All clinics & 5 & 57 & 2 \\
\hline 6 & Nurses & All Clinics & 5 & 43 & \\
\hline 7 & Students & All clinics & 15 & 64 & \\
\hline 8 & Grand Total & & 60 & 460 & \\
\hline
\end{tabular}

$\mathrm{P}$ value is $<0.05$.

Negative Control: Brand new Stethoscope which yielded no growth.

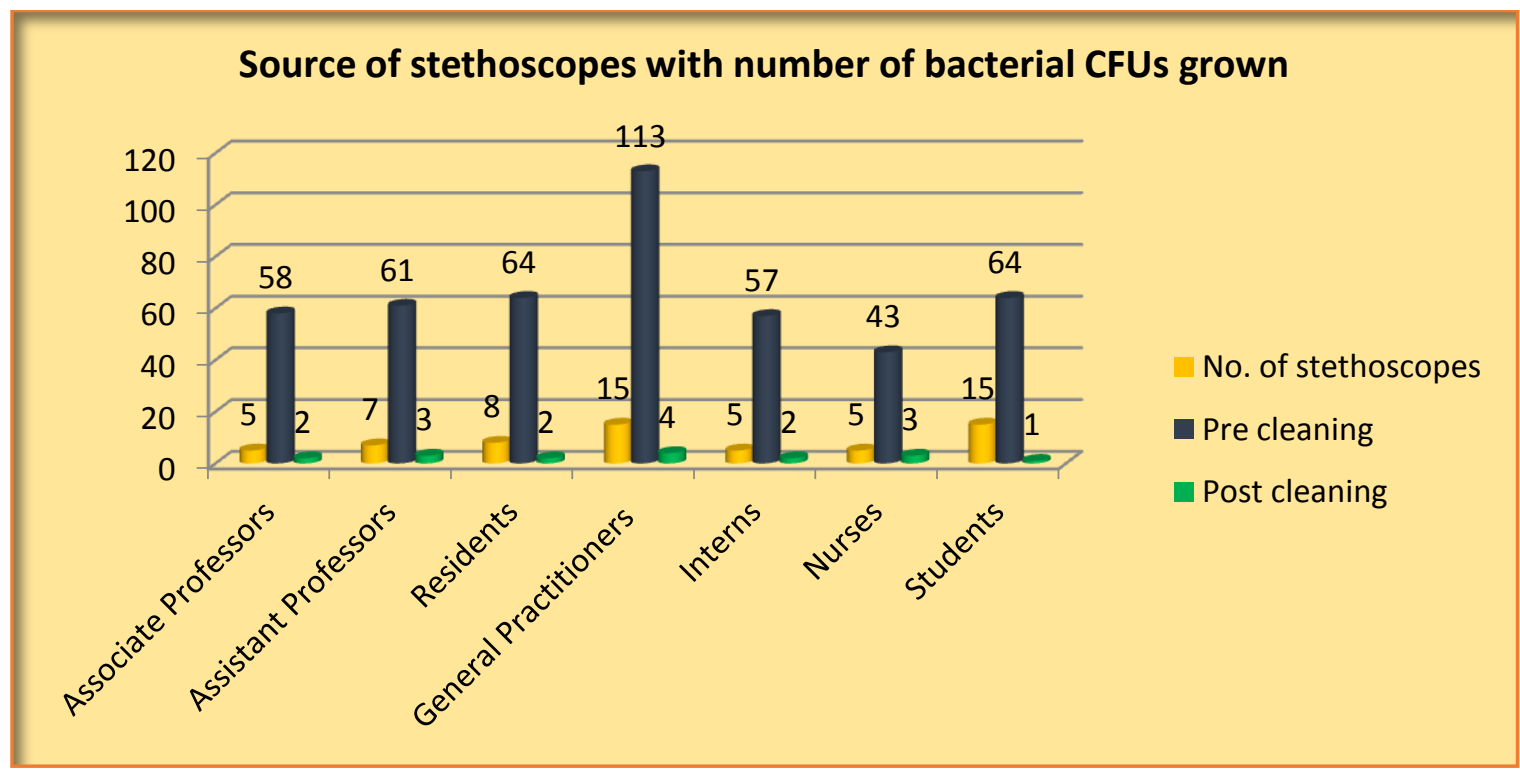

Fig: 1 
Table 3: Microbes Isolated

\begin{tabular}{|l|c|c|}
\hline S. No. & Name of the strain/s isolates & Number of colonies (CFUs) \\
\hline 1 & Staphylococcus aureus & 59 \\
\hline 2 & Staphylococcus epidermidis & 78 \\
\hline 3 & Micrococcus Spp. & 5 \\
\hline 4 & Streptococcus Spp. & 37 \\
\hline 5. & Enterococcus Spp. & 15 \\
\hline 6. & Escherichia coli & 5 \\
\hline 7. & Klebsiella Spp. & 9 \\
\hline 8. & Proteus vulgaris & 1 \\
\hline 9. & Pseudomonas aeruginosa & 6 \\
\hline 10. & Candida albicans & 4 \\
\hline 12. & Candida Spp. & 4 \\
\hline 13. & Aspergillus niger & 69 \\
\hline 14. & Bacillus Spp. & 135 \\
\hline 15. & Diptheroids & 33 \\
\hline & Grand total & 460 \\
\hline
\end{tabular}

$\mathrm{P}$ value is $<0.05$

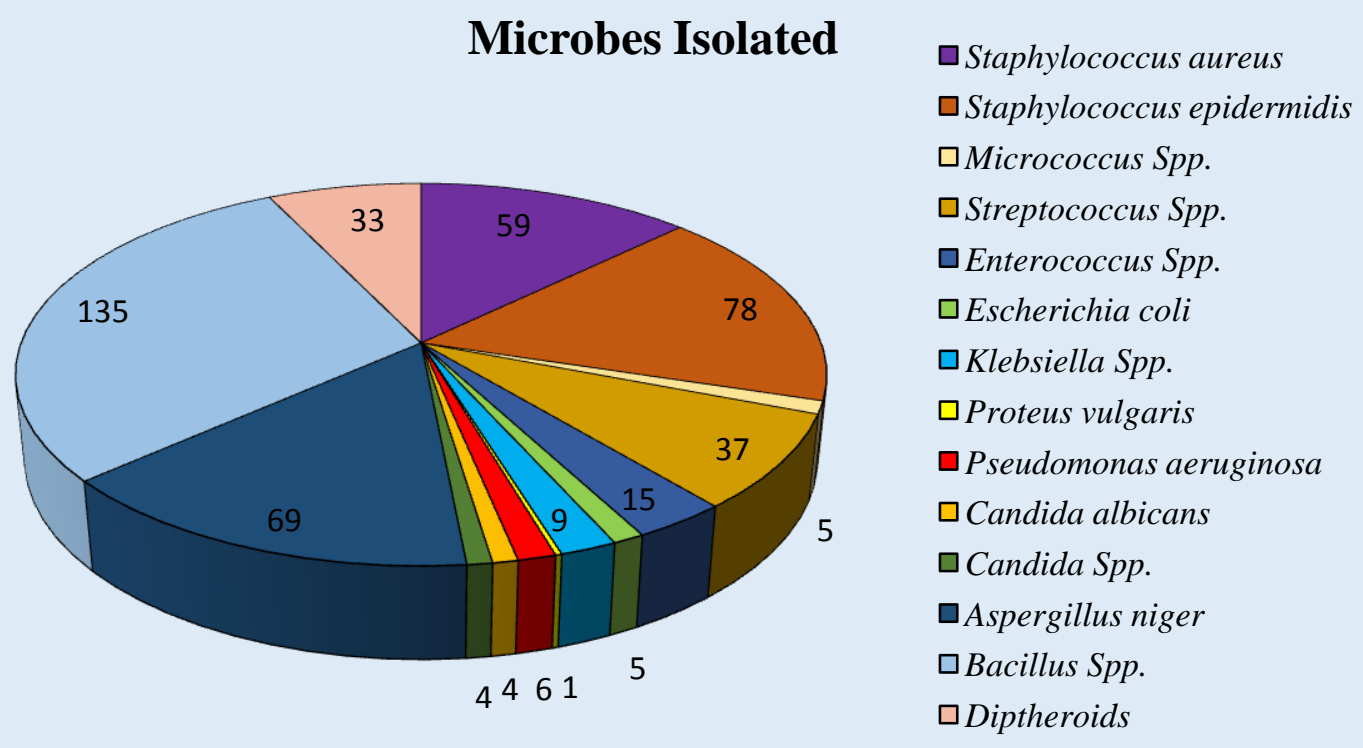

Fig: 2 Pie chart showing different microbes isolated

Healthcare workers were aware of nosocomial infection and seem to be following hand washing techniques and do clean their stethoscopes on a regular basis. However, students and Interns showed more awareness and disinfect or clean their stethoscopes more frequently than their counterparts. Students and interns carry the hand rub/disinfectant all the time with them which makes it handy and would prefer to disinfect their stethoscope very regularly. They prefer this to $70 \%$ isopropyl alcohol.

60 stethoscope samples yielded 460 CFUs which included pathogenic as well as non-pathogenic isolates which may by potential source of nosocomial infections. All (100\%) of them were contaminated with bacteria or fungi. When compared with a study $80 \%$ of the stethoscopes surveyed were contaminated ${ }^{5}$.

More non-pathogenic bacteria and fungi were isolated they were most likely of normal flora of the skin and may cause opportunistic infections in immunocompromised patients.

Post disinfection, few isolates (17) were grown which indicates that regular cleaning practice should be adapted by every healthcare worker which in turn will reduce the nosocomial infections.

Students stethoscopes $(n=15)$ and Interns $(n=5)$ showed less colonies of bacteria as they clean their stethoscopes more frequently (Table 1), than 
any other group. It indicates that younger generation is more aware of the nosocomial infections or the other participants of the study are ignorant.

When compared to the precleaning, 460 CFUs and Post cleaning/disinfection of the 16 colonies, there is a significant difference (Table 2). This proves that every healthcare worker must clean their stethoscopes regularly as the bacteria residing on the stethoscopes are potential pathogens and even some of them are normal flora of the skin, if they come in touch with the immunocompromised patients, the may cause opportunistic infections.

Table 3 summarises the bacteria and fungi isolated from the stethoscopes of healthcare workers of the area, which is lesson to be learnt to avoid nosocomial infection if enough measures are not taken.

Statistical analysis was done on IBM SPSS software and $\mathrm{P}$ value of $<0.05$ shows that study is statistically approved.

\section{Discussion}

Precleaning growth was quite significant (460 CFUs), and Post cleaning with isopropyl alcohol, there was a significant reduction in the CFUs. Alcohol based wipes were most commonly used to clean ststhoscopes ${ }^{6}$. Our study shows that stethoscopes do harbour bacteria,out of which some of them could be potential pathogens and some of them are normal flora $f$ the skin but can be potential source of opportunistic infections. Patients having poor immunity, immune compromised, with superficial infections, wound infections, burn patients are more likely to be affected if and when they come in touch with such contaminated stethoscopes. There is a increased risk of patients attending OPDs and in-patients of acquiring multi drug resistant bacteria. Following hand washing techniques and barrier protection remain the simplest and most effective infection control measures in the hospitals and outpatient clinics. If regular cleaning of stethoscopes are done which can help reduce the nosocomial infection as the number of bacteria will be reduced which is proved in this study.

\section{Conclusion}

All the Stethoscopes tested in the study carry bacteria and fungi on their diaphragm. The bacteria and fungi were pathogenic as well and non- pathogenic (normal skin flora) which may cause nosocomial infections. Results show significant reduction in bacterial counts after cleaning with $70 \%$ isopropyl alcohol. Hence cleaning with alcohol based swabs or at least one of the disinfectants or hand sanitizers to be used to ensure reduction in the number of microbes after consulting/use of stethoscope to avoid nosocomial infections. The study serves as a reminder to all healthcare professionals that the stethoscope they carry and use more than 10 hours a day can pose a potential threat of increasing nosocomial infections. And also that if they clean it with a suitable disinfectant can avoid the infections. As the number of drug resistant bacteria are ever increasing, we can prevent infections by cleaning the stethoscopes as one of the measures.

\section{References}

1. Waghorn DJ, Wan WY et al, Stethoscopes: a study of contamination and the effectiveeeness of disinfection procedures; British Journal of infection control;Vol 6 No.1, 2005.

2. Francis MC, Africa P et al.,Stethoscopes: A potential Source of Nosocomial Infections, Phil J Microbiol Infect Dis ,29(2);9-13,2000

3. Aodhan S B,David R J et al; Stethoscopes as possible vectors of infection by Staphylococci,BMJ,Vol 305,19-26, 1992.

4. Jeffrey S J, David Hoerle, Stethoscopes: A Potential Vector of Infection? Annals of Emergency Medicine 26:3, 1995.

5. Melinda A S,John J M et al, Arch Intern Med,151(1); 82-84,1996

6. Patrick H P, Andrew W, Examination of staphylococcal stethoscope contamination in the emergency department, CJEM 13(4): 239-244,2011. 